\title{
Alemania y el fin del sistema bipolar en política internacional
}

\begin{abstract}
R I C H A R D L Ö WEN T H A L es profesor de Relaciones Internacionales en la Universidad de Berlin. Fue Director del Otto Suhr Institut hasta 1967. Es coautor, con G. F. Hudson y Roderick MacFarquhar, de The Sino-Soviet Dispute (1961), y es el autor de Chruschtschew und der Weltkommunismus (1963). Además se ha desempeñado como columnista del diario The Observer, de Londres.
\end{abstract}

Quiero referirme a dos acontecimientos que están interrelacionados. El primero, ampliamente comentado a través de todo el mundo actual, es el fin del sistema bipolar; el aflojamiento de los dos grandes bloques de poder que han dividido al mundo desde la última guerra mundial. El segundo, en el momento actual, de captación mucho menos inmediata, es el redespertar del sentido de una identidad nacional alemana y la consiguiente búsqueda dirigida hacia una política nacional independiente entre los alemanes libres de la República Federal; siendo esta búsqueda una de las primeras consecuencias del relajamiento mencionado.

Se puede decir que Alemania como nación desapareció temporalmente después de la catástrofe a la cual el pueblo alemán permitió que Hitler lo arrastrase durante la última guerra. Alemania fue ocupada y dividida. Alemania Occidental formó una parte del murido occidental organizado, particularmente de Europa Occidental. Alemania Oriental, en cambio, formó parte del imperio soviético. Pero entonces no existía ningún país que pudiera denominarse "Alemania" y, durante un tiempo considerable, ni siquiera hubo mayor sentido de nacionalismo alemán. Contrasta este aspecto con la situación actual, en que los dos bloques sólidos -que habían engendrado los dos estados germanos- se tornan cada vez más fluidos e inestables; los propios alemanes han comenzado nuevamente a interrogarse a sí mismos en cuanto a quiénes son, dónde yace su futuro. Después de todo, no debe sorprender que, en momentos que los franceses bajo el general De Gaulle nuevamente sienten que primordialmente son franceses, y que los polacos bajo Gomulka sienten una vez más que son primordialmente polacos, los alemanes recuperen la sensación de ser alemanes. 
$\mathrm{E}_{\mathrm{s}} \mathrm{mi}$ intención referirme primeramente a los factores que determinaron este relajamiento de los bloques y la nueva constelación dentro de los asuntos mundiales, y luego a la reacción de Alemania ante este acontecimiento.

Me permito recordar que los dos grandes bloques de poder no son simplemente una consecuencia automática de la existencia de dos grandes poderes mundiales y de la distancia entre estos dos pafses $y$ todo el resto de los estados soberanos que subsistieron a la última guerra.

Es un thecho que existió y aún existe esta distancia, que existieron dos superpoderes $y^{\prime}$ que ambos tuvieron una cierta atracción automática y una probabilidad natural de ser más efectivos que otras potencias para ocupar el vacío de poder dejado por Hitler y Japón. Pero la competencia entre ellos y la formación de bloques no puede comprenderse sin una característica adicional: el hecho de que uno de estos dos grandes poderes, la Unión Soviética, no era simplemente un estado como cualquier otro, sino un gran poder ideológico; una potencia gobernada por un partido totalitario. Quiero decir que el Partido Comunista de la Unión Soviética habitualmente justifica su gobierno ante sí mismo y ante sus ciudadanos en términos que describen la necesidad de esparcir por todo el mundo su particular sistema político y social. De acuerdo con esto, el régimen comunista ha concebido siempre los intereses nacionales, los intereses de seguridad de la Unión Soviética, desde un aspecto particularmente ideológico. Es lo normal para cualquier gran poder, especialmente después de una guerra, desear llenar un vacío en sus fronteras antes de que enemigos potenciales lo ocupen. Es también normal para un gran poder que se ha visto atacado a través de una frontera vulnerable, desear instalar alli gobiemos amistosos, al otro lado de esta frontera. Pero es una peculiaridad del régimen soviético que considerase solamente a los gobiernos comunistas como gobiemos dignos de confianza $y$ que, por lo tanto, su interpretación particular de cuáles eran sus intereses de seguridad significara un deseo -contando con su poderío para llevarlo a efecto- de transformar el Este de Europa no sólo. en una esfera de influencia soviética, sino, ddemás, en una zona bajo el mando comunista.

- Esto significó que surgiera un bloque de un tipo nuevo y original; un bloque querse mantiene unido no simplemente gracias a la preponderancia de un gran poder hegemónico, sino además por el hecho de que los nuevos gobiernos en el área abarcada debieron su existencia como tales a un poder extranjero, dependiendo, por lo tanto, de la protección de un poder exterior para mantener su control 
interno. Esto es lo que se expresó con el término "régimen satélite", generalmente aplicado a los regímenes comunistas de Europa Oriental, aparte cle Ýugoslavia, durante muchos años. lin otras palabras, la alianza de los estados comunistas era básicamente diferente a otras alianzas; era mucho más sólida, mucho más rígida y sus estados miembros no contaron con la misma posibiliclad que los miembros de otras alianzas tradicionalmente han tenido, la de abandonar la alianza si no se satisfacían suficientemente sus intereses. En el hecho, nadie pudo por muchos años abandonar la alianza soviética, salvo que lo forzase un cambio interno de régimen, un cambio revolucionario. A la inversa, tal cambio revolucionario significaba un casus foederis, un móvil para la intervención soviética.

Ahora bien, este surgimiento de una alianza de un nuevo tipo ideológico provocó naturalmente una sensación de pelizgro entre los vecinos del bloque soviético. En toda Europa Occidental se hizo evidente una sensación de amenaza total e inmediata, no sólo a la seguridad nacional, sino también a las tradiciones, instituciones y valores de las democracias occidentales (y también de algunos estados que no eran democracias). Entonces se produjo una contraalianza, afianzada en su unión por este sentido de amenaza inminente. Esta contraalianza, orAN, no ha llegado hasta el mismo grado ideológico, ni tampoco ha logrado la misma homogeneidad. No todos los estados miembros de la OTAN son capitalistas en el tradicional sentido de la librc empresa; no todos los estados miembros, por otra parte, son democracias libres, en la misma medida que lo son los principales países de la otAN. Pero aunque no tha existido una homogeneidad ideológica, social, económica o política absoluta, se ha logrado sí una peculiar estabiliclad en el transcurso de varios años en la contraalianza occidental.

Esta estabilidad la produjeron dos factores: la sensación de amenaza inminente, que ya he mencionado, y la sensación de protección absoluta contra esta amenaza otorgada inicialmente por el monopolio nuclear de Estados Unidos y, más tarde, por la clara superioridad norteamericana en el campo del poder atómico. Todo esto, siempre que Estados Uniclos se encontrase solo en el dominio de ese poder o fuese muy superior a la Unión Soviética, no solamente por el factor cantidad sino, además, por no ser efectivamente vulnerable a las armas nucleares soviéticas (situación que existió por lo menos hasta 1958), y siempre que la sensación de protección de Ja alianza norteamericana entre los estados europeos fuese casi absoluta. Como resultado, la alianza occidental también tuvo una poco usual estructura cohesiva, aun en época de paz; necesitó únicamente 
recordar la existencia de una estructura de comando conjunta $y$ de una infraestructura conjunta en época de paz: factores nuevos en la historia de las alianzas.

Esta estructura bipolar, que se difundió desde Europa hacia el mundo, se ha ido aflojando gradualmente por una cantidad de acontecimientos que han minado; por un lado, el sentido de cohesión ideológica èn èl Este, y en consecuencia el sentido de peligro inmediato en Occidente; y por otro lado, la sensación de protección absoluta que el poder norteamericano inspiraba a Europa Occidental. Deseo mencionar primero la pérdida de autoridad ideolágica de los soviéticos dentro del bloque. El hecho de que Khrushchev, para lograr adaptar los métodos del régimen comunista a la etapa de desarrollo industrial alcanzada por la Unión Soviética, haya decidido que había que destruir el mito de la infalibilidad de Stalin, sin saberlo y sin quererlo, echó a tierra de un golpe el mito de la infalibilidad de la Unión Soviética y del Partido Comunista Ruso, entre comunistas de otros estados. Tampoco ahora la apariencia coherente de la autoridad ideológica soviética ha sido restablecida, como fue sin embargo restituido ol poderío f́sico soviético en Europa Oriental después de la crisis de octubre de 1956. Incluso, la unión externa del bloque fue, en un comienzo, reintegrada solamente por medio de la ayuda ofrecida por la autoridad intacta del líder comunista chino Mao Tse-tung. Pero los comunistas chinos aprendieron con esto que se iniciaba ahora la posibilidad de disputar la autoridad soviética. Tomaron cuidadosa nota de este hecho para utilizar su enseñanza durante una situación en la cual sus intereses nacionales y los de la Unión Soviética chocaban más y más a menudo.

Junto a la pérdida de autoridad ideológica, se encuentra la pérdida de homogeneidad ideológica en el seno del bloque comunista, debido sobre todo al desarrollo divergente de la Unión Soviética y China Comunista. Ya he mencionado la importancia de la destalinización. El ajuste gradual de Rusia post-Stalin ante las realidades de la vida diaria en una sociedad industrial moderna, necesitó un aminoramiento del papel jugado por la fuerza física en el régimen; por lo tanto, una declinación de su dinamismo revolucionario. Stalin utilizó la fuerza para transformar la sociedad soviética, tal como un cirujano utilizaría su bisturí en una operación. Pero bajo sus herederos el papel de la coerción ha disminuido constantemente en favor del papel de los incentivos. Y si acaso se estudia el nuevo programa del partido adoptado por el Partido Comunista de la Unión Soviética en 1961, durante su Vigésimosegundo Congreso, se encontrará que en este programa se establece que la lucha de clases interna 
dentro de la Unión Soviética ha terminado, que el estado ha cesado de ser una dictadura del proletariado y se ha transformado en "un estado de todos los trabajadores". La intención de estás frases es reasegurar a los ciudadanos soviéticos, trabajadores y campesinos, intelectuales y burócratas, el que pueden continuar,su labor diaria en paz, a salvo no sólo de súbito arresto y deportación, sino, además, de nuevos y grandes trastornos sociales organizados desde la cima del partido. La tarea del estado ya no es la de transformar por la fuerza a la sociedad, sino más bien administrar los resultados de la revolu: ción e incrementar la producción.

En China, en cambio, tenemos un país comunista aún en las etapas arcaicas y diff́ciles de la industrialización y un régimen que eștá convencido de que, durante estas etapas diffciles iniciales, debe exigir duros sacrificios a su población, y que logrará mantenerse e imponer estos sacrificios solamente si se obtienen constantemente un clima de fortaleza sitiada, un clima de lucha incesante y eterna vigilancia contra enemigos tanto externos como internos. Mao hasta ha dicho que China deberá continuar esta lucha interna "por cinco a diez generaciones, o uno o varios siglos". Lo que ha cambiado entre la Unión Soviética y China, entonces, no es sólo la erosión de la autoridad soviética, sino además la tendencia radicalmente divergente del desarrollo ideológico y social dentro de los dos grandes estados comunistas. $Y$ esto, junto a las divergencias cada vez más conscientes de intereses nacionales, ha llevado a una creciente tensión y, finalmente, al virtual rompimiento de la alianza entre la Unión Soviética y China Comunista.

Estos acontecimientos -pérdida de autoridad ideológica soviética y rompimiento del bloque soviético-chino- han producido a su vez grandes repercusiones en la posición de los estados comunistas de Europa Oriental. Han sido explotados por estos regimenes, para obtener una mayor libertad de movimiento y concesiones que en parte ofreció la Unión Soviética espontáneamente y en parte se vio forzada a dar. O sea, que han servido a estos gobiernos para logtar que la vida sea cada vez más tolerable para sus súbditos y aumentar asi su base popular. Nuevamente, cuanto más firmes han sido sus bases, mayor ha sido su capacidad para enfrentarse con la Unión Soviética en asuntos de interés nacionàl. En otras palabras, emanciparse del estadio de satélites y llegar a ser bastante independientes interiormente, aunque en el exterior continúen como aliados dependientes. El imperio satélite de Stalin ha sido así transformado en algo muy cercano a una clásica alianza bajo un poder hegemónico - un poder 


\section{E S T U D I O S I N T E R N A G I O N A L E S}

en ejercicio del liderato- en virtud de su superioridad regional militar y económica más bien que por factores puramente icleológicos.

Paralela a esta transformación del bloque oriental de Europa, la actitud internacional del régimen soviético mismo ha producido importantes repercusiones. Ya se ha mencionado una de las causas de esta transformación: el desgaste del dinamismo interno revolucionario, el sentir que la función principal del régimen debería ser ahora una concentración en el fomento de la productividad y mejoramiento de nivel de vida de la población; un cambio asi sin lugar a dudas habría de debilitar la importancia del factor ideolágico incluso en la política externa soviética. Un segundo factor encaminado en la misma dirección ha sido el éxito de la política occidental de contención. El hecho de que, no obstante la posesión de cohetes intercontinentales y bombas de hidrógeno, la Unión Soviética no haya podido lograr lo que Khrushchev pensó sería capaz de obtener: una enorme preponderancia en los asuntos mundiales, en los años iniciados con el ultimátum de Berlín de 1958 y que finalizaron con la crisis de los misiles en Cuba, 1962.

Asi es como los líderes soviéticos se han encontrado en la situación de ser incapaces, a pesar de su actual eminencia tanto económica como militar, de obtener la preponderancia mundial. Han llegado entonces a la conclusión que, si se considera esta situación desde el punto de vista de su desarrollo interno, ya no existe una mayor urgencia de predicar el evangelio internacional. $Y$ finalmente - factor de máxima importancia - han aprendido, debido al conflicto con China y a los efectos de éste sobre otros estados comunistas, que el surgimiento de nuevas revoluciones y nuevos estados socialistas no contribuye necesariamente al poder y grandeza de la Unión Soviética. Cuando Khrushchev formalizó su primer acuerdo con China en 1954, él aún creía que existía una especie de armonía preestablecida entre los podëres comunistas; que bastaba con darles un trato de iguales independientes para asegurarse que marcharian al unfsono con Rusia en los asuntos internacionales. Desde entonces, hubo de aprender que no podía controlar la política exterior de China y que debería realizar enormes esfuerzos para evitar que fuese China quien controlase la política externa rusa a través de su presión ideológica. También debió aprender que ni siquiera podía controlar totalmente la política externa de la castrista Cuba, a pesar de que Castro dependía completamente de la protección militar soviética y sus subsidios económicos. Hubo de aprender además que tampoco podía controlar un pequeño país vecino como Rumania. La conclusión de que la llegada del comunismo a nuevas naciones no aumentaria obligadamente cl 
Richard Löwenthal / Alemania y cl fin del sistema bipolar en politica internacional

poder mundial de Rusia fue inevitable. El resultado es que todos estos factores - madurez industrial interna, contención efectiva desde el Occidente, decadencia pluralística en el movimiento comunista internacional- han convergido para que la Unión Soviética sea casi un poder satisfecho, aunque esta satisfacción se deba únicamente al hecho de haber devorado sobrepasando en algo sus posibilidades digestivas.

Esta transformación del bloque soviético y de la política externa rusa ha disminuido naturalmente, en Europa Occidental y Estados Unidos, el sentido de una amenaza inminente o un peligro inmediato a la independencia e instituciones de los estados de Europa Occidental. Al mismo tiempo, y paralelo a esto, la sensación de protección absoluta del poder norteamericano también ha disminuido, ya que el misile intercontinental también permite que, por lo menos en principio, los Estados Unidos sean vulnerables ante las armas nucleares soviéticas. Desde entonces, las represalias en masa han dejado de ser la respuesta ante cualquier clase de amenaza soviética. Esto, a su vez, provoca inevitablemente una nueva conciencia de los distintos intereses nacionales dentro de la alianza occidental.

Otros factores han trabajado en la misma dirección. Tal vez el más importante ha sido la dispareja ejecución de la descolonización. Todos los estados de Europa Occidental poseian colonias que habrian de perder. Todos debieron vérselas con el problema de ceder sus imperios coloniales en forma ordenada. Algunos de ellos se resistieron activamente al desmantelamiento de su imperio colonial. Por contraste, Estados Unidos se preociupaba de que la lentitud en descolonizar pudiese dañar la causa occidental en su competencia con el bloque comunista; de ahí que estuviera ansioso por lograr que se acelerase al máximo el proceso de descolonización. Como resultado, ha habido un buen número de conflictos de intereses; de los cuales el más dramático fue la crisis de Suez, clurante la cual -como es sabido- Estados Unidos se unió al Tercer Mundo y a la Unión Soviética contra algunos de sus aliados occiclentales de Europa. Con toda certeza, no es un mero accidente que Francia. haya tomado la decisión de desarrollar su propia bomba atómica, aun antes de la subida al poder del general De Gaulle, iniciativa del socialista Mollet después del asunto de Suez.

Han existido otras discrepancias dentro de la Alianza Occidental respecto a la velocidad y forma de descolonización y la liquidación de intereses privilegiados creados en las antiguas colonias. Por ejemplo, ha habido divergencias en conexión con la secesión de Katanga del antiguo Congo Belga en 1960/61, y con el apoyo político norteamericano a la independencia de Indonesia y después de Argelia. 
Aunque ya el proceso de descolonización toca a su fin, la conciencia de estas diferencias en los intereses nacionales se ha agudizado entre los miembros de Europa Occidental de la oTAN, en el momento que la protección estratégica de sus territorios por Estados Unidos contra todo tipo de ataques sovieticos demostró ser menos absoluta. En efécto, desde el advenimiento del cohete intercontinental, las discrepancias en torno a la estrategia por seguir se han sumado a las anteriores diferencias de intereses: mientras los europeos occidentales, conscientes de que su territorio está expuesto a ser devastado y sus libertades destruidas hasta por un ataque puramente convencional, desearían utilizar las armas nucleares como disuasión contra todo tipo de agresión, Estados Unidos, para quien solamente una guerra nuclear presenta un peligro serio, ha insistido en elevar el umbral nuclear para cualquier acción que se inicie en favor de sus aliados.

Este conflicto de intereses éstratégicos entre los europeos occidentales, tal como lo representan De Gaulle y algunos de los líderes de Alemania Occidental, y los Estados Unidos ( y el conflicto paralelo de estrategia entre la Unión Soviética y China, que se evidenció durante la crisis de Quemoy de 1958) tiene su contrapartida en la creciente conciencia del interés conjunto de Estados Unidos y la Unión Soviética en evitar una guerra nuclear. Este interés cnmún fue abiertamente admitido por primera vez durante la cớnferencia cumbre de Ginebra en 1955 y demostró su potencial estabilizador del statu quo durantę la revolución en Hungria de 1956; también desempeñú un papel cada vez más importante después del desarrollo de los misiles intercontinentales. El hecho de reconocer la existericia de tal interés común no significa que el gran conflicto de intereses existente entre los dos superpoderes haya desaparecido, tal como el ultimátum de Khrushchev en Berlín, en 1958, y la crisis de los misiles en Cuba, el año 1962, lo han demostrado; pero no significa que, aunque continúen con su conflicto, no estén conscientes de la necesidad de limitar sus formas si desean sobrevivir. En años recientes este interés común en la supervivencia ha encontrado su expresión en ciertas líneas de acción comunes, tal como la conclusión del tratado de prohibición de pruebas nucleares y las negociaciones hacia un tratado de no-proliferación nuclear. En conjunto, estos cambios than contribuido a propagar una conciencia algo exagerada dentro de Estados Unidos de que el conflicto Este-Oeste tradicional con la Unión Soviética está bastante pasado de moda y añejo, a la vez que, una correspondiente sensación entre. los europeos occidentales de que la otan ya no es capaz de actuar como centro coordinador de toda su 
política exterior y que deberán ahora prestar mayor atención a la persecución de sus respectivos intereses nacionales.

Este devenir general ha sido enormemente acelerado por el surgimiento de un importante tercer factor en los asuntos mundiales: la transformación de China Comunista en un poder absolutamente independiente. China Roja, en este momento, no es aún, a pesar de sus explosiones nucleares, un poder mundial a la misma escala, o del mismo rango, que Estados Unidos y la Unión Soviética, pero es un factor totalmente independiente dentro de los asuntos internacionales. Ya no es posible dar por sentado que la Unión Soviética y China estarán siempre unidos ante cualquier posible conflicto futuro. Hoy en día podemos observar que, a pesar de todas las polémicas, la Unión Soviética y China están de hecho unidas contra Estados Unidos en Vietnam. También podemos observar que la Unión Soviética y Estados Unidos están unidos contra China Roja en todo lo concerniente a la India. Y si por un momento imaginásemos la muy poco probable situación de un intento soviético de intervención a la fuerza contra la.independencia nacional de Rumania, bien podríamos igualmente imaginar alguna situación en que Estados Unidos y. China se uniesen contra la Unión Soviética. Menciono esta probabilidad (mụy improbable porque los soviéticos son incapaces de actuar tan atolondradamente) solamente para establecer bien claramente que la constelación mundial ha dejado de ser bipolar, siendo ahora cuando menos triangular. En realidad, ambos grandes superpoderes deben actualmente interrogarse, ante cualquier situación producida, a cuál de sus conflictos deberán otorgar prioridad: al antiguo entre ellos o al nuevo con China. Esto introduce una nueva flexibilidad dentro de la situación. Provee a cada uno de los poderes líderes de los bloques tradicionales con nuevas oportunidades para maniobrar politicamente. Pero también introduce un factor adicional de posible divergencia en el seno mismo de las antiguas alianzas.

Por ejemplo, la alianza occidental actualmente posee teóricamente la posibilidad de decidir si acaso se abocará eni primer término a sus antiguos conflictos con la Unión Soviética o si dedicará su mayor atención al nuevo problema de China Roja. En la práctica, la alianza occidental no ha decidido nada por este estilo: los norteamericanos han llegado ya a su decisión y los europeos occidentales han decidido algo diferente. En realidad, aunque no expresamente, los norteamericanos han dedicado cada vez mayor prioridad al escenario del $\mathrm{Pa}$ cifico, al conflicto con China Comunista y al conflicto en Vietnam, el que ellos perciben como ligado con el conflicto con los chinos. Para los europeos, en cambio, es este un asunto lejano y distante si 
se compara con sus relaciones con la Unión Soviética, que verdaderamente consideran materia de máxima urgencia. Este ha sido otro factor del aflojamiento de la alianza occidental y ha contribuido enormemente a una situación donde, aunque no existe un rompimiento dentro de la alianza occidental ni siquiera aproximadamente equivalente a la ruptura producida entre la Unión Soviética y China, el aflojamiento, la desintegración interna de la alianza occidental, son ya en la actualidad considerablemente mayores que los producidos dentro del bloque Europa Oriental-Unión Soviética. El bloque soviético en Europa -a pesar de todo su debilitamiento, de todas sus transformaciones- es aún mucho más unido que la alianza occidental actual.

Pero todos estos desarrollos no implican que el conflicto entre la alianza occidental y la Unión Soviética -aunque se encuentre en receso- haya desaparecido. Para poder comprender esto, deberán observarse cúáles son los grandes propósitos que incluso la satisfecha Unión Soviética tiene respecto a Europa. La Unión Soviética desearia mantener todo lo que ya obtuvo, mantener su estructura de poder hasta el río Elba, incluyendo al estado de Alemania Oriental creado artificialmente por ella misma. Al mismo tiempo, la Unión Soviética desearía obtener una détente con el Oeste de tal amplitud que se lograse hasta el caso extremo de que la alianza otan con Estados Unidos y Europa Occidental se disolviese totalmente y los norteamericanos volviesen a su patria. Si se pudiera imaginar que ambos propósitos de la Unión Soviética se lograsen simultáneamente, se tendría una situación en que la Unión Soviética sería el poder preponderante en el continente europeo. La Unión Soviética no serfa capaz de mantener su actual estructura de poder sin destacar tropas hasta el mismo rio Elba, dado que el estado de Alemania Oriental es el único miembro de su bloque que ha mantenido el estado de satélite, en el sentido de no ser autosuficiente. Alemania Oriental no puede confiar en que lograría mantenerse tal cual es sin contar con el apoyo soviético, y todo esto por la buena y sencilla razón de que, al mismo tiempo que el resto de los estados comunistas en Europa han llegado una vez más a ser estados nacionales, o sea, que han adquirido una creciente identificación entre el pueblo y el régimen, el estado de Alemania Oriental no es un estado nacional. Es en realidad una unidad artificialmente separada de una nación y su régimen no tiene posibilidad alguna de producir una identificación nacional efectiva. En consecuencia, el mantenimiento de este estado requiere la presencia continuada de tropas soviéticas o, por lo menos, el continuado derecho soviético de intervención unilateral en esta área, $Y$ una situación tal, en que las fuerzas soviéticas se mantuvieran 
a orillas del Elba cuando los norteamericanos se repatriaranj significaría una preponderancia soviética en Europa.

El peligro de esta situación, con toda probabilidad, no radicaria en que la Unión Soviética la aprovechase militarmente para ocupar toda Europa. Ni siquiera podría suceder que ellos hoy en dia intentasen muy seriamente fomentar la revolución comunista en Europa Occidental. Pero sí significaría que los estados de Europa Occidental se hallarian en una situación tal que penmitiría a la Unión Soviética ejercer presión, coaccionar eficazmente en los asuntos de su mayor interés, y que los recursos de Europa Occidental cada vez más rápidamente integraran parte de la esfera soviética de poder, en el mismo sentido en que los recursos de la Finlandia neutral y no comunista son efectivamente parte de la esfera soviética de poder. En otras palabras, el logro de los fines soviéticos - completa disolución de las alianzas basadas en el statu quo territorial- significarła la "finlandización" progresiva de Europa Occidental. Menciono esta posibilidad para demostrar que el conflicto de propósitos entre la política soviética y la política occidental en Europa, aunque haya cambiado su forma, aunque se haya tornado menos ideológico, no ha terminado y no ha sido solucionado. Puede que haya entrado al campo de lo soluble, pero hasta este momento, la verdad es que no se ha encontrado la respuesta.

En una situación asi, el aflojamiento progresivo y la desintegración efectiva de la alianza occidental han producido graves efectos sobre Europa en general, y sobre Alemania Occidental en particular. La estructura de la otan ha sido debilitada por la decisión del general De Gaulle de retirarse de la organización militar integrada de ella. Se ha debilitado aún más en el transcurso de los dos últimos años por la creciente preocupación de Estados Unidos por el escenario de operaciones del Pacífico y por una correspondiente mayor ausencia de una activa política norteamericana en Europa. No es tanto la sensación de cétente lo que ha debilitado a la OTAN. Una política de clétente que se dirigiese hacia un mejoramiento de las relaciones con la Unión Soviética y Europa Oriental, como parte de un concepto general de arreglo en Europa, bien podría tornarse en el tema, el contenido principal de la actividad de la otan. Pero lo que hemos vivido durante los últimos tres años no ha sido tanto una política de délente, sino más bien una cétenté sin una línea de acción; y este ha sido otro factor de la desintegración.

Ahora me encamino hacia una discusión sobre cuáles han sido los efectos de estos acontecimientos en Alemania, sobre la República Federal, sus ciudadanos y su política nacional. Primeramente, estos 
acontecimientos imposibilitan totalmente la continuación de la política tradicional de la República Federal. Esa política tradicional, tal como la concibió Adenauer, se orientó, en general, principalmente hacia la completa integración de Alemania Occidental dentro de la estructura de la alianza occidental, y también dentro de una Europa Occidental cada vez más federalizada, en particular. Ese camino se ha bloqueado eficazmente, principalmente por la decisión del general De Gaulle de que no exista una Europa federalizada. También lo obstaculiza el aflojamiento de la oran. Como resultado, la opinión píblica en Alemania, en los últimos años, ha girado cada vez más $f$ ecuentemente hacia lo que yo en un comienzo denominé "un senLido de identidad nacional", una concentración en el problema alemán; una tendencia hacia colocar la unidad germana primero y luego la integración occidental; hacia preocuparse más que nada con el destino de los 17 millones de habitantes bajo el mando comunista en Alemania Oriental.

Este redespertar del sentido de identidad nacional podría, por supuesto, haberse tornado en el punto de partida para un nuevo nacionalismo agresivo. Podría haber llevado al tipo de peligro, recientemente muy discutido en la prensa internacional, del surgimiento de un partido nacionalista en Alemania. En realidad, la tendencia principal tha ido en la dirección opuesta. Particularmente en lo que se refiere a las relaciones con los vecinos orientales de Alemania. Ha existido una conciencia general, ante todo, de que no hay ninguna manera de solucionar el problema alemán sálvo que sea dentro de un esquema de détente general Este-Oeste. Hubo, indudablemente, gran oposición inicial a este concepto de détente que tuvo una acción dilatoria dentro del gobierno de Alemania y de la opinión pública alemana, pero ya ha. sido totalmente superada. Aparte de algunas reacciones de retaguardia aisladas, existe la convicción de que la solución del problema alemán solamente será factible dentro del marco de una solución general europea; hecho que quitaría la barrera entre las dos Europas. Esto es algo que actualmente se acepta libremente en Alemania. El corolario de dicha situación es que no puede llegarse a solución alguna del problema alemán, ni encontrar camino alguno hacia su unificación, sin el total mejoramiento de las relaciones entre Alemania $y$ sus vecinos orientales. Esto significaría que cualquier esperanza o intención de revisar las fronteras orientales de postguerra de Alemania, la línea Oder-Neisse, deberá ser abandonada.

Tal visión la han mantenido en privado la mayoría de los políticos alemanes responsables durante varios años, pero no han estado 
deseosos de expresarla públicamente por el temor de perder el sólido bloque de votantes, llamado de los "cabilderos expulsados", organizaciones de aquellos alemanes que originalmente fueron expulsados desde los territorios más allá del Oder y Neisse, ocupados actualmente por los polacos. Estas organizaciones, que cuentan con millones de miembros, han tenido un poder verdaderamente efectivo sobre los dos grandes partidos de la República Federal durante varios años; consiguiendo por lo menos el apoyo verbal a sus exigencias de mayores revisiones de fronteras. El gran cambio en este campo sucedió durante los últimos dos años $y^{\prime}$ su pionero ha sido la Iglesia Evangélica Alemana.

En un memorándum publicado en octubre de 1965, esta institución exhortaba al pueblo alemán a dejar de ser farisaicos respecto a los sufrimientos de los refugiados, y dedicarse a recordar también los sufrimientos de los polacos bajo Hitler; no pensar sólo en los derechos de los expulsados a recobrar su patria, sino también no olvidar los derechos de los ocupantes polacos que han vivido ya por 20 años en estos territorios; concentrarse en su nueva patria y poner en primer lugar la necesidad de una reconciliación con Europa Oriental. Después de que este memorándum fue publicado y discutido apasionadamente, el clima político en Europa Occidental cambió totalmente sobre esta interrogante vital. Desde aquel entonces los gxandes partidos democráticos han logrado hablar en forma muchisimo más honesta y franca con el electorado en relación a una politica real hacia Polonia. El aumento reciente de los votos nacionalistas de oposición, en varias elecciones regionales, se debe en una medida considerable al hecho de que los desencantados nacionalistas, que anteriormente votaban por los grandes partidos, se encuentran actualmente dentro de un partido de oposición separado del resto. En este sentido, considero que tal desenvolvimiento es muy sano. Porque es mejor que una minoría nacionalista, y es ésta una minoría comparativamente limitada, se coloque separadamente antes de que tenga el poder de chantajear a los grandes partidos democráticos.

Paralela a esta creciente concentración en el problema de la unificación de Alemania, también ha aumentado el realismo, tanto en el tema de la détente como de las relaciones con los vecinos orientaleș de Alemania. Sin embargo, la admisión de que la política rígida ha fallado no abre aún el camino a una nueva política. Dado el debilitamiento general de la cohesión interna de la alianza occidental, la mayor concentración en los problemas alemanes se ha acompañado últimamente de un mayor sentido de frustración y una creciente búsqueda de un papel que los alemanes libres pudiesen des- 
arrollar en la solución de su propio problema nacional. Al hacerlo, los ojos alemanes se han tornado por supuesto hacia sus grandes aliados y hacia sus conceptos sobre las nuevas relaciones Este-Oeste necesarias para finalizar con el conflicto. Mas los alemanes se encuentran confrontados con dos conceptos, uno norteamericano y otro francés, que en sus distintas maneras son insatisfactorios desde el punto de vista alemán.

El concepto americano de la détente se explica en forma muy completa en el discurso del Presidente Johnson de octubre de 1966. Es este un concepto de reducción gradual de las tensiones militares y de mejoramiento de los contactos económicos, culturales y personales entre Europa Oriental y Occidental, entre Ios reglmenes comunistas y nocomunistas, para crear asi un clima en el cual las grandes interrogantes políticas puedan eventualmente llegar a resolverse. Pero este concepto no indica ningún fin del camino, no contiene tampoco proposiciones para el reemplazo final de los bloques, y queda bien claro que el problema de Alemania no podrá ser solucionado hasta el día en que las dos alianzas militares ya no se confronten más en el campo europeo.

Este último punto se destaca mucho más precisamente en la visión del general De Gaulle: él propugna que se reemplacen las dos alianzas militares que actualmente existen, por lo que llama "un sistema de seguridad europeo". Este sistema de seguridad europeo, mencionado por el general De Gaulle, y sobre el cual discute con los soviéticos, no toma dentro de su mente la misma forma que adquiere en la de los soviéticos. El concepto soviético de lo que debe ser un sistema de seguridad europeo propone la disolución de las alianzas, $y$ la retirada de los norteamericanos de toda Europa sobre la base del statza quo. El concepto de De Gaulle, en la medida en que es discernible, propone reemplazar las alianzas con un sistema de garantías centralizadas en torno a un Tratado de Paz Alemán, tratado que, de uno u otro modo, posibilitaría la reunificación de Alemania, condicionada a garantías de seguridad dadas a sus países vecinos, reconocimiento de sus fronteras y limitación de los armamentos alemanes. Bajo tal tratado, ambos grandes poderes podrian garantizar protección a los estados vecinos contra una Alemania nuevamente unida, y, a la vez, garantizar a la nueva Alemania únida contra posibles intervenciones unilaterales desde cualquier extremo. Esta visión, aunque sea muy difícil de realizar $-y$ obviamente no se divisa como un plan a corto plazo- contiene el enorme mérito de mostrar una posible solución del conflicto Este-Oeste y no solamente circunscribirse a un aflojamiento gradual y a una reducción de tensiones. Este es el 
gran atractivo que ejerce sobre los alemanes de hoy. Porque los alemanes necesitan la convicción de que el túnel en que se hallan no es sin fin. Pero por muy atractiva que aparente ser la visión de De Gaulle para el pueblo alemán, la polftica práctica degaullista no lo es en absoluto, debido a que no sólo ha debilitado unilateralmente la alianza occidental mucho antes de que se efectuase negociación alguna encaminada hacia una solución, sino que, además, su principal falla radica en no considerar que la participación de Estados Unidos es fundamental para lograr una solución. Sin embargo, una solución tal como la arriba esquematizada - solución que, de hecho, significaría que la Unión Soviética cedería su control sobre Alemania Oriental y, por lo tanto, perdería una importante posesión- no es en absoluto factible salvo que el peso total de Estados Unidos se haga sentir sobre el proceso de negociaciones. Ia verdadera necesidad - por sobre cualesquiera garantías y compensaciones que indujeran a la Unión Soviética a aceptar finalmente tal solución del problemasería el reconocimiento de que ésta es la única oportunidad para terminar con el problema de la confrontación rusa con el poder militar norteamericano en Europa. En otros términos, es esencialmente necesario convencer a los soviéticos de que no pueden simultáneamente mantener Alemania Oriental y deshacerse de los norteamericanos y de la alianza otan, sino que están obligados a elegir. Esto resulta posible únicamente si existe una polftica común occidental que se oriente hacia tal propósito.

Este argumento me lleva a mi conclusión respecto al papel que podría :jercer la República Federal de Alemania en la nueva situación mundial. La República Federal Alemana no podrá jamás lograr sus fines nacionales por sł misma, solamente lo hará si reintegra una cierta medida de cohesión a la alianza occidental. Sin embargo, la cohesión de esta alianza no podrá ser restaurada por medio de una vuelta atrás a lo que tal alianza fue antiguamente, durante los peores momentos de la guerra frła. O sea, una perspectiva de rigidez militar puramente defensiva. La unión se recuperará solamente por medio de un concepto de solución del conflicto que sea común a todo Ocridente, por un programa de negociación diplomática común. En fin, por una idea común sobre lo que serla la constitución del acuerdo necesario para la paz europea y alemana.

Este arreglo, en el futuro, serviría a los intereses de todos los poderes occidentales, pero en ningún caso reviste para cualquiera de ellos la importancia vital que tiene para Alemania.

En consecuencia, la probabilidad de que se logre producir una política occidental unificada del tipo expuesto, depende en gran 
narte de la posibilidad de una iniciativa alemana. Es mi opinión que el cambio del gobierno alemán, la formación de una "Gran Coalición", dẹbe ser contemplado como una oportunidad que crea esa posibilidad al otorgar al gobierno la amplia y sólida base requerida para tal acción. Debido a que este cambio sobrevino en momentus que el antiguo régimen había obviamente caído en un callejón sin salida, la política rígida ha sido finalmente abandonada. Pero cualquier línea de acción nueva por medio de la cual la República Federal apremie a sus aliados hacia el desarrollo de un concepto común para un Tratado de Pàz Europeo y Alemán, claramente impondrá sacrificios a los alemanes.

Será necesario quc, por lo menos dentro de los consejos occidentales, pongan sus cartas sobre la mesa y digán francamente cuál sería el precio que estarían dispuestos a pagar por la reunificación. A qué están dispuestos para dar seguridad a sus vecinos sobre problemas fronterizos, problemas de armaméntos, etc. Una política así no se puede adoptar sino sobre bases amplísimas por un tipo de coalición amplia tal como la recientemente formada. Sin embargo, la nueva situación exige que Alemania no sólo demuestre una nueva flexibilidad hacia el Este y una nueva disposición hacia la mejor comprensión mutua.

También éxige un mayor sentido de independencia, la clara conciencia de que Alemania no logrará sus legítimos fines nacionales si acaso simplemente confía ya sea en los norteamericanos o en los franceses, o quien sea, sino que debe desarrollar su propia contribuición, su propio sentido del interés nacional y sus propias iniciativas. Creo yo que la tendencia de la opinión en Alemania Occidental y también la polftica de Alemania Federą ante esta situación de aflojamiento de los bloques tradicionales se orientará en esta dirección: hacia una iniciativa de Alemania para lograr obtener la solución constructiva del problema de Europa y Alemania. 